\title{
The Spatio-Temporal Evolution of Integrated Network of Zhongyuan Urban Agglomeration
}

\author{
Song Qiong \\ College of Urban and Environmental Sciences \\ Northwest University \\ Xi'an 710127, China \\ Han Jing \\ College of Urban and Environmental Sciences \\ Northwest University \\ Xi’an 710127, China
}

\author{
Du Juan \\ College of Urban and Environmental Sciences \\ Northwest University \\ Xi’an 710127, China \\ Zhao Xinzheng* \\ College of Urban and Environmental Sciences \\ Northwest University \\ Xi'an 710127, China
}

\begin{abstract}
On the basis of combing the progress of urban network research, the network contact matrix of Zhongyuan urban agglomeration is constructed from the comprehensive network evaluation index system and the improved gravity model from 2000 to 2015, the spatio-temporal evolution characteristics of integrated network are analyzed by means of social network analysis. The main conclusions are as follows: (1) From 2000 to 2015, the development characteristics of radiation and agglomeration in the integrated network of Zhongyuan urban agglomeration are increasingly obvious. (2) The central city of Zhengzhou has been in a growing position. The axis of network development has evolved from the cross type composed of Beijing-Guangzhou and Lianyungang-Lanzhou to the " $\mathrm{H}$ " type of Beijing-Guangzhou, Lianyungang-Lanzhou and ChangzhiLuoyang. (3) Network participation in $\mathbf{3 0}$ cities has increased in varying degrees, and the gap between the first and last city has widened. (4) Luoyang and Handan grew into regional central cities, the development of eastern and southern parts of the region is slower, and the hierarchical network system is obvious.
\end{abstract}

Keywords-Integrated network; Spatio-temporal evolution; Zhongyuan urban agglomeration

\section{INTRODUCTION}

The urban network takes the city as the network node, and takes the dynamic "urban flow" as the communication mode. The ultimate aim is to realize regional resource sharing and network economy, and promote the coordinated development of the region as a whole. The GaWC network group led by Taylor has carried out a great deal of research on the network structure of the major cities in the world ${ }^{[1]}$, and gradually went deep into the regional network, such as Daniels P W and so on, taking the Asia Pacific region as an example to analyze the relationship between urban transformation and industry ${ }^{[2]}$; Derudder B et al. studied the relationship changes of 132 cities around the world from 2000 to 2008, and explored their impacts on urban and regional levels ${ }^{[3]}$. Influenced by the research of $\mathrm{GaWC}$, domestic scholars have also carried out a lot of research on urban network from the perspective of economic contact network ${ }^{[4]}$, transportation network ${ }^{[5]}$, and information network ${ }^{[6]}$. At present, the research on the network structure of Zhongyuan urban agglomeration mainly focuses on economic connection ${ }^{[7]}$ and passenger flow ${ }^{[8]}$. Overall, the current urban network research has the following characteristics: First, the research area is more partial to the higher level of urbanization development, which is not thorough enough for the central and western regions represented by the Zhongyuan urban agglomeration, especially the large gaps in the development level of cities and towns, including the large area of rural areas. Second, both domestic and foreign studies tend to describe the current structural characteristics, and there are few studies based on long time sequence evolution.

Based on the above background, the paper takes the urban areas of 30 cities of Zhongyuan urban agglomeration as the object, chooses 2000, 2005, 2010, 2015 four years, uses the comprehensive evaluation index system of urban network, calculates the urban contact matrix by the improved gravity model, and uses the social network analysis method to make the system analysis of spatio-temporal evolution characteristics of integrated network of the Zhongyuan urban agglomeration, in order to enrich and develop the content of the urban network research, at the same time to provide a reference for the optimization of the spatial structure of the Zhongyuan urban agglomeration.

\section{DATA AND MeTHODS}

\section{A. Data}

According to "Zhongyuan urban agglomeration development plan”, the scope includes five provinces and 30 cities. The basic geographical unit of the paper is the urban districts of 30 cities (Fig. 1). The data of population and social and economic development are mainly from the "China City Statistical Yearbook” in 2001-2016 years. Since Jiyuan has no districts, all indicators are based on city data, which is derived from the "Henan statistical yearbook" in 2001-2016 years. The

Foundation: Graduate Student Innovation Project of Northwest University, No.YZZ17148.

Corresponding author: Zhao Xinzheng, E-mail: xzzhao@nwu.edu.cn. 
spatial distance comes from the Intergovernmental highway mileage of Baidu maps.

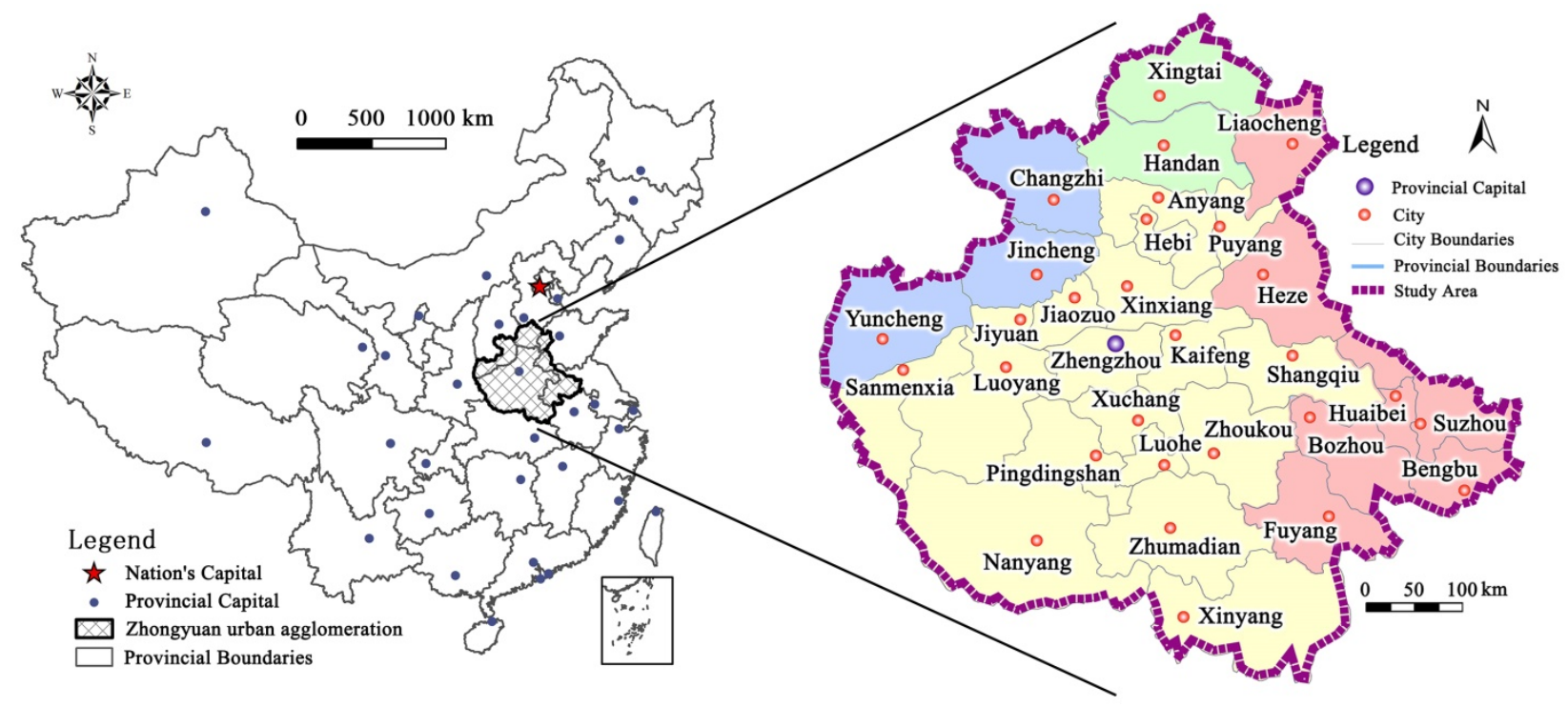

Fig. 1 Study area

\section{B. Methods}

The comprehensive urban network evaluation index system (TABLE I) is constructed from the aspects of basic scale, economic development, facilities construction, social life, ecological environment and spatial distance.

TABLE I. THE EVALUATION INDEX SYST EM OF COMPREHENSIVE URBAN NETWORK

\begin{tabular}{|c|c|c|}
\hline Objective Level & $\begin{array}{c}\text { Subsystem } \\
\text { Level }\end{array}$ & $\begin{array}{l}\text { Indicator } \\
\text { Level }\end{array}$ \\
\hline \multirow{5}{*}{$\begin{array}{l}\text { Urban } \\
\text { comprehensive } \\
\text { strength }\end{array}$} & Basic Scale & $\begin{array}{l}\text { Nonagricultural Population; } \\
\text { Area of Built Districts; }\end{array}$ \\
\hline & $\begin{array}{c}\text { Economic } \\
\text { Development }\end{array}$ & $\begin{array}{l}\text { Per Capita GDP; Investment in } \\
\text { Fixed Assets; Tertiary Industry } \\
\text { Product; Value-Added by } \\
\text { Industry; Amount of Foreign } \\
\text { Capital Actually Utilized; }\end{array}$ \\
\hline & $\begin{array}{c}\text { Facilities } \\
\text { Construction }\end{array}$ & $\begin{array}{l}\text { Per Capita Area of Paved } \\
\text { Roads in City; Number of } \\
\text { Public Transportation Vehicles } \\
\text { per } 10000 \text { Population; }\end{array}$ \\
\hline & Social Life & $\begin{array}{l}\text { Average Wage of Employed } \\
\text { Staff and Workers; Students } \\
\text { Enrollment of Regular } \\
\text { Institutions of Higher } \\
\text { Education Per } 10000 \text { persons; } \\
\text { Number of Doctors per } 10000 \\
\text { Population; Total Retail Sales } \\
\text { of Consumer Goods; }\end{array}$ \\
\hline & $\begin{array}{c}\text { Ecological } \\
\text { Environment }\end{array}$ & $\begin{array}{l}\text { Per Capita Area of Green } \\
\text { Land; Green Covered Area } \\
\text { as \% of Completed }\end{array}$ \\
\hline Urban distance & $\begin{array}{c}\text { Spatial } \\
\text { Distance }\end{array}$ & Road mileage \\
\hline
\end{tabular}

1) Improved gravity model.

In order to reflect the directional characteristics of intercity relations, an improved gravity model is applied to measure the temporal and spatial relations of urban agglomeration. The calculation formula ${ }^{[9]}$ is

$$
C_{i j}=K \frac{\left(\sum_{h=0}^{n} W_{i-h} \times P_{i-h}\right) \times\left(\sum_{f=0}^{n} W_{j-f} \times P_{j-f}\right)}{D_{i j}}
$$

In the formula, $C_{i j}$ is the connection value between $i$ and $j$ city; $K$ is the constant of gravity; $W_{i-h}$ and $W_{j-f}$ are the factor weight values that affect the strength of the cites $i$ and $j ; P_{i-h}$ and $P_{j-f}$ are the factor quantization values that influence the strength of $i$ and $j$ in cities; $D_{i j}$ is the spatial distance of cities.

2) Social network analysis method.

a) Network Density. Network density reflects the density of the network connection as a whole. The calculation formula ${ }^{[10]}$ is

$$
D=\sum_{i=1}^{k} \sum_{j=1}^{k} \frac{d\left(n_{i}, n_{j}\right)}{k(k-1)}
$$

In the formula, $D$ is the network density, $K$ is the number of cities, $d\left(n_{i}, n_{j}\right)$ is the relationship between cities.

b) Absolute centrality. The absolute centrality is the sum of the relationship between city A and all other cities. It is divided into outdegree and indegree. The calculation formula ${ }^{[10]}$ is

$$
C\left(n_{i}\right)=\sum_{j=1}^{n} X_{i j}
$$

In the formula, $C\left(n_{i}\right)$ is outdegree or indegree, $X_{i j}$ indicates the connection value of the cities $i$ and $j$.

\section{EVOLUTION CHARACTERISTICS OF INTEGRATED NETWORK}

\section{A. Global evolution characteristics}

Using Arcgis10.2 to draw the integrated network space contact map of the Zhongyuan urban agglomeration (Fig. 2), to clearly reflect the evolution trend of the integrated network, the line of the connection value $<2$ is not shown in the diagram. Based on the connection value in 2015, we use Jenks method to 
divide the contact lines from big to small into five levels: Level 1 contact (>36.888), level 2 contact (20.900 36.888), level 3 contact (12.164 20.900), level 4 contact (6.709 12.164), and
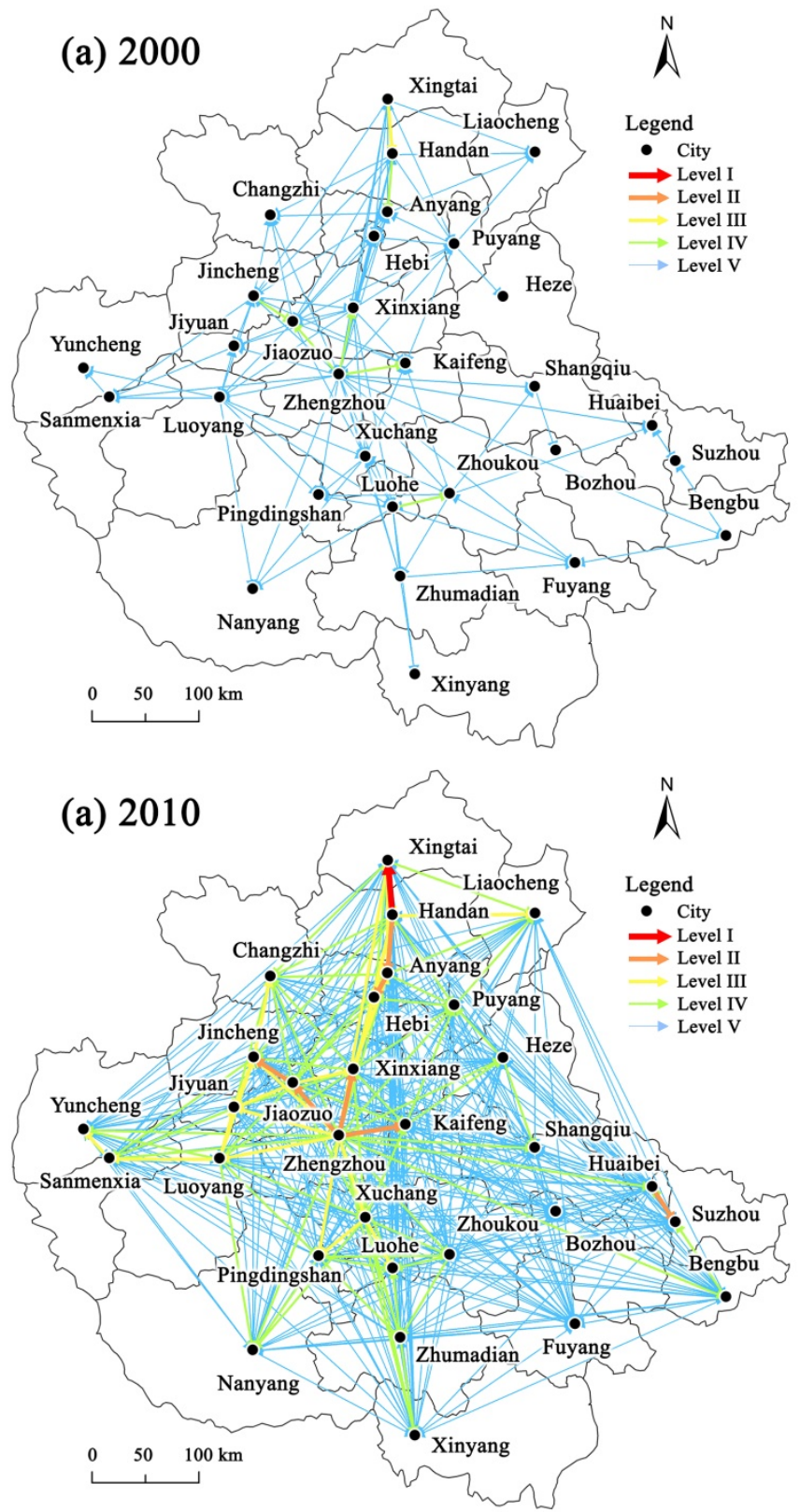

level 5 contact (2.000 6.709). According to the network density and contact level, we analyze the static network hierarchy characteristics of urban agglomeration.
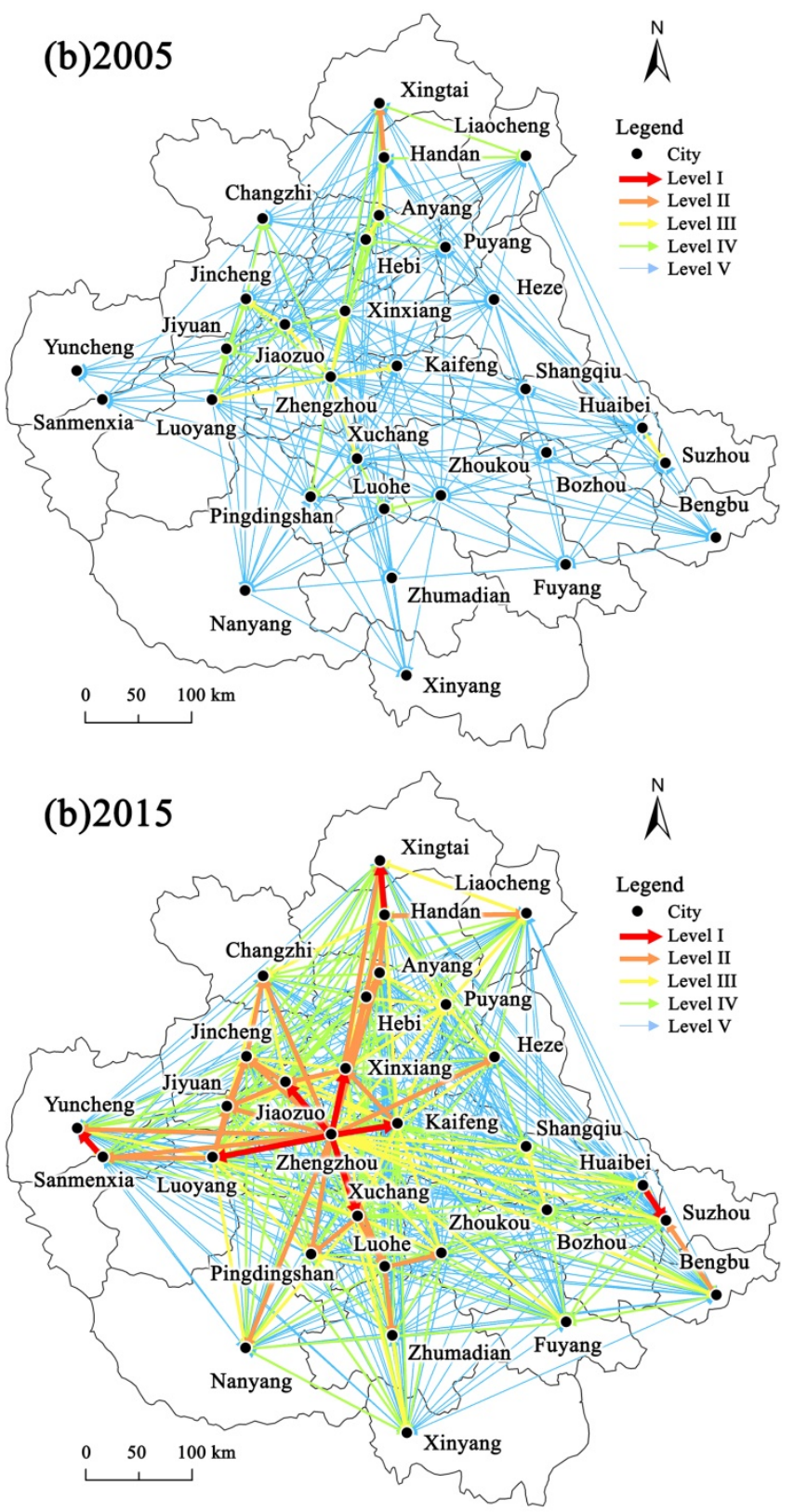

Fig. 2 The spatial relation of static networks in zhongyuan urban agglomeration from 2000 to 2015

(1) The development level of integrated network is gradually improving, and the interaction development between radiation and agglomeration is obvious. The network connection lines of urban agglomeration increased from 116 in 2000 to 650 in 2015, and the network density increased from 0.133 in 2000 to 0.747 in 2015. In 2000, the urban agglomeration had three $\sim$ five level contact lines. At this time, the integrated network was in the primary stage and the network connection was looser, and the main performance was the radiation from Zhengzhou to outward, the space was stronger in the north than in the south. In 2005, the urban agglomeration had two $\sim$ five level contact lines. By this time, the integrated network connection was still weak. While the radiation effect of Zhengzhou increased, the connection between the adjacent cities was also increasing, and the space showed that the north was stronger than the south, the west was stronger than the east. In 2010, five levels of contact lines all appeared, the integrated network was in a rapid growth stage, and the urban connection tended to be close. With Zhengzhou as the center, the central cities cluster of 7 cities appeared, including Kaifeng, Xinxiang, Jiaozuo, Jiyuan, Luoyang, Pingdingshan and Xuchang. In 2015, the integrated network was further developed; the high level contact lines increased obviously and extended along the Beijing-Guangzhou and the 
Lianyungang-Lanzhou lines, the interaction between cities was frequent. The radiation range of 8 cities in Zhengzhou, Kaifeng, Luoyang, Xinxiang, Xuchang, Jiaozuo, Handan and Jincheng had covered the whole area.

(2) The status of Zhengzhou as central city is continuously enhanced, and the " $\mathrm{H}$ " type network structure with the core backbone of Beijing-Guangzhou, Lianyungang-Lanzhou and Changzhi - Luoyang is forming. Relying on the location advantage of the center zone and the political advantage of the provincial capital city, Zhengzhou has a stable central position in the integrated network. The radiation intensity of the urban agglomeration appears to be a trend of decreasing outer circle with Zhengzhou as the center. From the spatial pattern and temporal sequence to observe the three development axis, the earliest formation of the Beijing-Guangzhou axis is also the strongest. The regional development axis of BeijingGuangzhou, Lianyungang-Lanzhou cross is unchanged, and the Changzhi - Luoyang axis is still developing.

\section{B. Cities evolution characteristics}

According to the indegree and outdegree of the cities (TABLE II), the evolution characteristics of the integrated network nodes are analyzed.

TABLE II. THE ABSOLUTE DEGREE OF ST ATIC NETWORKS IN ZHONGYUAN URBAN AGGLOMERATION FROM $2000-2015$

\begin{tabular}{|c|c|c|c|c|c|c|c|c|}
\hline \multirow[b]{2}{*}{ Cities } & \multicolumn{2}{|c|}{2000} & \multicolumn{2}{|c|}{2005} & \multicolumn{2}{|c|}{2010} & \multicolumn{2}{|c|}{2015} \\
\hline & OutDegree & InDegree & OutDegree & InDegree & OutDegree & InDegree & OutDegree & InDegree \\
\hline Zhengzhou & 85.626 & 6.402 & 207.950 & 22.248 & 343.922 & 65.909 & 823.865 & 164.026 \\
\hline Kaifeng & 22.108 & 22.184 & 23.241 & 46.584 & 106.998 & 88.400 & 341.958 & 153.219 \\
\hline Luoyang & 20.929 & 17.031 & 105.650 & 24.193 & 181.075 & 60.768 & 357.594 & 139.905 \\
\hline Pingdingshan & 0 & 16.707 & 14.036 & 42.142 & 110.583 & 82.863 & 119.478 & 177.032 \\
\hline Anyang & 14.042 & 32.442 & 31.110 & 69.876 & 98.986 & 120.501 & 151.018 & 197.109 \\
\hline Hebi & 2.189 & 25.361 & 14.876 & 76.311 & 51.541 & 142.749 & 117.447 & 223.230 \\
\hline Xinxiang & 35.371 & 16.122 & 82.518 & 44.911 & 169.368 & 90.440 & 290.090 & 172.541 \\
\hline Jiaozuo & 32.249 & 23.649 & 95.386 & 45.840 & 186.670 & 85.544 & 241.966 & 177.076 \\
\hline Puyang & 15.733 & 14.571 & 40.010 & 45.248 & 54.792 & 108.643 & 86.139 & 193.030 \\
\hline Xuchang & 13.810 & 20.279 & 104.425 & 27.819 & 198.964 & 61.955 & 299.061 & 142.901 \\
\hline Luohe & 30.698 & 12.392 & 16.352 & 40.201 & 33.110 & 112.951 & 162.462 & 156.477 \\
\hline Sanmenxiang & 5.937 & 13.614 & 6.700 & 29.965 & 38.622 & 103.665 & 120.092 & 160.123 \\
\hline Nanyang & 0 & 9.683 & 10.709 & 29.995 & 16.675 & 91.654 & 108.224 & 132.961 \\
\hline Shangqiu & 2.076 & 4.141 & 4.845 & 22.706 & 19.264 & 83.708 & 34.215 & 178.529 \\
\hline Xinyang & 0 & 5.995 & 0 & 20.816 & 9.614 & 93.193 & 29.832 & 171.383 \\
\hline Zhoukou & 16.846 & 11.904 & 29.965 & 33.894 & 72.277 & 85.143 & 119.623 & 161.769 \\
\hline Zhumadian & 5.779 & 15.198 & 6.135 & 31.265 & 49.397 & 95.208 & 69.250 & 180.683 \\
\hline Jiyuan & 4.345 & 24.801 & 23.383 & 66.052 & 69.058 & 123.993 & 99.350 & 228.209 \\
\hline Xingtai & 31.501 & 9.297 & 52.876 & 46.421 & 141.622 & 106.431 & 122.444 & 185.275 \\
\hline Handan & 35.356 & 21.706 & 98.673 & 35.417 & 246.383 & 80.952 & 300.934 & 134.072 \\
\hline Liaocheng & 0 & 11.985 & 26.230 & 34.843 & 36.879 & 92.492 & 138.626 & 120.585 \\
\hline Heze & 0 & 2.744 & 24.310 & 40.145 & 69.674 & 82.373 & 107.066 & 156.694 \\
\hline Huaibei & 6.003 & 7.931 & 25.392 & 34.886 & 84.109 & 69.254 & 158.507 & 133.327 \\
\hline Bozhou & 0 & 2.076 & 0 & 17.124 & 2.021 & 63.927 & 40.563 & 174.917 \\
\hline Suzhou & 0 & 9.406 & 6.039 & 32.974 & 13.900 & 88.066 & 46.248 & 206.177 \\
\hline Bengbu & 10.180 & 2.383 & 17.603 & 29.846 & 74.081 & 50.768 & 163.158 & 110.482 \\
\hline Fuyang & 2.362 & 10.023 & 4.311 & 21.567 & 10.977 & 85.225 & 33.171 & 169.129 \\
\hline Changzhi & 0 & 14.424 & 16.271 & 51.923 & 79.533 & 93.758 & 127.327 & 165.824 \\
\hline Jincheng & 34.843 & 15.331 & 55.061 & 55.864 & 128.090 & 98.012 & 200.093 & 177.288 \\
\hline Yuncheng & 0 & 8.200 & 0 & 20.981 & 5.939 & 95.580 & 36.953 & 202.783 \\
\hline
\end{tabular}

Found: (1) The degree of network participation in each city has gradually increased, and the polarization gap has gradually expanded. In the past 2000-2015 years, the degree of indegree and outdegree in each city increased significantly. In 2000, there were 9 cities with an indegree / outdegree of 0 , and no such cities after 2010. Meanwhile, the outdegree increased from 85.626 in 2000 to 790.694 in 2015, and the indegree increased from 30.366 in 2000 to 117.727 in 2015 . The number of cities with more outdegree than indegree increased from 11 fluctuations in 2000 to 12 in 2015, among which Zhengzhou, Luoyang, Xinxiang, Handan and Jiaozuo were always extraversion cities.

(2)The regional central cities in Luoyang and Handan are gradually formed, and hierarchical network system appears. The status of Zhengzhou's extraversion center is stable. 
Luoyang and Handan have been rising continuously in the past 15 years, forming the regional radiation center. Kaifeng increased its position rapidly after 2005, and jumped to second place in the region in 2015. However, the status of Zhoukou and Puyang declined significantly. The cities of Shangqiu, Nanyang, Zhumadian, Xinyang, Zhoukou, Bozhou, Fuyang, southern and eastern cities of Zhongyuan urban agglomeration lack strong driving force and extraversion cities, and the speed of development is slightly lagging behind.

\section{CONCLUSION AND DiscUSSION}

\section{A. Conclusion}

The paper analyzes the spatio-temporal evolution characteristics of integrated network of Zhongyan urban agglomeration from two aspects of the whole and the nodes in 2000-2015 years. The main conclusions are as follows:(1) The development level of the integrated network of Zhongyuan urban agglomeration is gradually increasing, and the interactive development trend of radiation and agglomeration is obvious.(2) The status of Zhengzhou as network center is stable, the development axis of urban agglomeration from two lines composed of Beijing-Guangzhou and Lianyungang-Lanzhou evolution to three lines composed of Beijing-Guangzhou, Lianyungang-Lanzhou and Changzhi-Luoyang, among which the Beijing-Guangzhou axis is the highest level. And Zhengzhou, Kaifeng, Xinxiang, Jiaozuo, Jiyuan, Luoyang, Pingdingshan, Xuchang show the advantages of urban cluster.(3) The network participation of 30 cities have different degrees of promotion, and the polarization gap between the first and last cities is widening.(4) Luoyang and Handan have become regional central cities, while the cities in the Eastern and southern of the urban agglomeration, Nanyang, Zhumadian, Xinyang, Zhoukou, Bozhou and Fuyang lack of strong driving force cities, the speed of development is slightly lagging. The hierarchical network system of Zhongyuan urban agglomeration has been obvious.

\section{B. Discussion}

Urban network is a complex giant system. This paper only analyzes the evolution of integrated urban network with the help of macro statistical data. It will be the next research direction to combine the dynamic flow data such as Internet data, information flow data, capital flow data and statistical data to make a comprehensive comparison of urban network.

\section{REFERENCES}

[1] Taylor P J. World City Network: A Global Urban Analysis [J]. New York: Routledge.2004.

[2] Daniels P W, Ho K C, Hutton T A. Service industries and Asia-Pacific cities: New development trajectories [M]. London: Routledge.2005.

[3] Derudder B, Taylor P J, Ni P, et al. Pathways of change: Shifting connectivities in the world city network, 2000-2008[J]. Urban Studies, 2010, 47(9): 1861-1877.

[4] Wu k, Fang C L, Zhao M X. The spatial organization and structure complexit of Chinese intercity networks [J]. Geographical Research, 2015, 34(4):711-728.(In Chinese)

[5] Liu C L, Duan D Z, Yu R L, et al. Topological Structure Evolution and Complexity of Urban-rural Road Network in Wuhan Metropolitan Area [J]. Scientia Geographica Sinica, 2014, 34(4): 401-410. (In Chinese)

[6] Ding Z W, Zhou K Y, Kang J J, et al. The spatial differentiation and influencing factors of the service quality of C2C stores in Central China: A case study of five types of Taobao online stores [J]. Geographical Research, 2016, 35(6):1074-1094. (In Chinese)

[7] Li Y T, Pan S Q, Miao C H. Structure and evolution of economic linkage network at county level in Central Plains Economic Zone [J] Geographical Research, 2014, 33(7):1239-1250. (In Chinese)

[8] Liu Z B, Liu J Y, He X P, et al. The Spatial Connection and Network Feature of Zhongyuan Economic District Base on Intercity Traffic Flow [J]. Economic geography, 2014, 34(7):58-66. (In Chinese)

[9] Qian C L, Ye J, Lu C. Gravity zoning in Wuhan Metropolitan Area based on an improved urban gravity model [J]. Progress in Geography, 2015, 34(2):237-245. (In Chinese)

[10] Liu J. Overall network analysis notes: UCINET software practical guide [M]. Shanghai: Truth \& WisdomPress.2009. (In Chinese) 